\title{
PROVIDE: A Pedagogical Reference Oracle for Virtual IntegrateD E-ducation
}

\author{
V.Lakshmi Narasimhan, Shuxin Zhao, Hailong Liang, \\ and Shuangyi Zhang \\ The University of Newcastle, NSW, Australia
}

\author{
lakshmi.narasimhan@newcastle.edu.au
}

\section{Executive Summary}

This paper presents an interactive educational environment for use over both in situ and distancebased modalities of teaching. Several technological issues relating to the design and development of the distributed virtual learning environment have also been raised. The PROVIDE framework proposed in this paper is a seamless distributed environment for continuous interaction between teaching and learning. The four learning facets, namely, the things learned from a teacher, learned by students' using their own intellect, learned through peer-interaction and learned through the process of hands-on experience, are all enhanced in the framework by the provision of the "third dimension" in learning. The latter mechanism facilitates learning activities to be observed and monitored through effective co-operation and collaboration through various tools and technologies. Further, the PROVIDE framework introduces the concept of offering alternate courses, learning choices and managing related academic processes, such as testing and certification. Some implementation details and related algorithms have also been provided in this paper.

Keywords: On-line education portal, Distributed IT services and technologies, distance based learning, PROVIDE framework.

\section{Introduction}

The advent of the Internet has opened up several new opportunities in distance learning. Several major educational institutions and private sector participants are infusing educational innovation for the 21 st century and expanding their mission to include activities through on-line education. The Internet and related technologies are now providing a means to have timely data available to anyone who needs them, which has in turn diminished traditional institutional boundaries for access to expert knowledge. For example, students can liaise with experts, enter libraries and engage in chat room discussions with knowledgeable individuals on almost any topic. These new opportunities provide the impetus to rethink how knowledge is discovered and develop new designs of systems for on-line education. According to the U.S. Congress for Technology Assess-

Material published as part of this journal, either on-line or in print, is copyrighted by the publisher of the Journal of Information Technology Education. Permission to make digital or paper copy of part or all of these works for personal or classroom use is granted without fee provided that the copies are not made or distributed for profit or commercial advantage AND that copies 1) bear this notice in full and 2) give the full citation on the first page. It is permissible to abstract these works so long as credit is given. To copy in all other cases or to republish or to post on a server or to redistribute to lists requires specific permission and payment of a fee. Contact Editor@JITE.org to request redistribution permission. ment (US Congress, 2004), distance education refers to 'linking of a teacher and students in several geographic locations via technology that allows for interaction'. Harasim, Hiltz, Teles, \& Turoff (1995) state that the use of computer conferencing indeed provides a useful adjunct to large multimedia courses. Course tutors held discussion groups in closed conferences with relatively small numbers of 
students. Interestingly, the computer conferencing forum that was open to all students and tutors purely for socializing purposes generated the most traffic and became the most productive workspace. This unanticipated outcome opened up significant new avenues for practitioners of on-line education (Maehl, 2000). Interestingly, distance education institutions have not necessarily embraced on-line learning, but when they did, the transition to a communication-based technology has often gone more smoothly because of the overlap of values and skills required to succeed in the virtual setting. Indeed the growth and development of distance education is closely associated with the growth and development of Information Technology (Rowan, Barllell, \& Evans, 1998).

\section{Related Works}

Several researchers have raised the fundamental question of "who is a virtual student?" It has been assumed that it is predominantly learners who take on-line courses because on-line learning allows them to continue the delivery of any time, anywhere education. According to Gilbert (2001), a "typical" on-line student is generally described as "being over twenty-five years of age, employed, with some higher education already attained, and equally likely to be either male or female. On-line students may be non-traditional undergraduate, graduate, or continuing education students. Studies by Carr (2000) have shown that the very elements that draw students to on-line classes - convenience in a busy work schedule, ability to continue to attend to family demands are the elements that interfere with their ability to remain enrolled. The virtual student is not hindered by the absence of auditory or visual cues in the communication process. In fact, he or she may be freed up by the lack of visual barriers that can hinder face-to-face communication. In addition, virtual students feel comfortable expressing themselves and contributing to a discussion through largely text-based means. This does not mean that the virtual student must possess exceptional writing skills to begin on-line study. Peterson (2001) reports that some instructors have found the writing skills of students improved with ongoing participation in on-line courses.

Palloff and Pratt (2001) note that instructors need to pay closer attention to the following indicators so that they do not miss them in an on-line class:

- Changes in level of participation

- Difficulty even getting started with the course

- Flaming other students or the instructor, meaning the inappropriate expression of emotions, particularly anger and frustration

- Dominating the discussion in inappropriate ways

When we add on-line teaching and learning to a mix of students - knowing that different types of students take on-line courses - the following four activities seem to facilitate learning:

- One-Alone Activities: Doing Internet research, including using on-line databases and journals, participating in listeners related to course material, receiving information via email from on-line groups producing information related to course material, and applying prior knowledge or learning are a few such activities.

- One-To-One Activities: These include doing independent studies, doing internships, taking correspondence courses, and making learning contracts.

- One-To-Many Activities: These include on-line lectures, whiteboard sessions, and online symposia using audio or video produced by the instructor.

- Many-To-Many Activities: They include discussion groups, listeners, and the discussion board; debates on critical or controversial issues in the course content; simulations; role 
plays; case studies; and collaborative group projects, which can take the form of small group research projects, discussions of cases, simulations, or role plays.

The diversity of distance learning and teaching with supporting technologies has been researched and discussed over the past decade. Many pedagogical models on distance learning have been proposed and some of them have already been implemented and put in use. Further, as noted before, the way in which on-line technology becomes operational, however, differs significantly from institution to institution. According to Harasim (1998) there appear to be three levels of technology that relate to continuing education:

- As the primary teaching mechanism for one or more courses;

- As an enhancement to traditional face-to-face courses;

- As a forum for discussions and information exchange with peers and experts and a means of accessing on-line resources

In the following paragraphs, we review some of these model technologies:

Kouki and Wright (1999) provide a description of the vast range of Internet tools, such as E-mail, www web, chat rooms etc, which are commonly used to build up a tele-learning environment. These tools fall into two main groups to support two kinds of communication in distance learning, namely, asynchronous communication and real time communication. Kouki \& Wright (1999) also discuss the common ways for delivery of course materials and related information including textbook, assignments and learning instructions, which are mainly in the hypertext and hypermedia format available for students downloading or browsing. They also discuss on-line simulation of class sessions, which can by carried out in two ways: (1) asynchronous lecture, which utilizes web pages in hypertext or hypermedia format with glossaries, indexes, exercises and references and (2) synchronous lecture and class discussion, which exploits Internet relay chat, MUD, or conferencing software to simulate the dynamic communication. Ling et al. (2001) explore the result of a survey of the current situation in distance education carried out by Australia universities.

Ganesan, Edmonds, and Spector (2002) present the challenge of designing a large-scale, networked and distributed learning environment and instructional system. Their system aims to provide support for communication and co-ordination in addition to providing a degree of control on what the learners do and think, through the tracking of learners' activities and progress towards their personal goals. They note that the instructor-led workshop is giving way to hybrid course design that includes a combination of technology-mediated events and more traditional classroom events. They suggest that distributing specific course events and activities ahead of a particular lesson would be much more worthwhile than placing the entire course on-line. Fritze, Welch, and $\mathrm{Ji}$ (2000) describe the components required for implementing on-line learning activities that are customizable for local disciplines, styles and discursive pedagogical interactions. Core to their framework is the "State Description Protocol for describing and recording the state of arbitrary learning activities". Through this implementation, "a learner's actions can be recorded, analysed, restored, annotated or utilized by others through their activity pages". This mechanism provides the flexibility in educational design so that collaborative sharing can be maximized.

Mayes, Dineen, Mckendree, and Lee (2002) propose a system in which several software components are used to capture, store and retrieve records and outputs of real learning episodes and make these available for new learners. This idea is based on the premise that the experience of watching other students learn helped the new learner to model one's learning more effectively. They also demonstrate how the idea might be exploited in practice by their design of a system called "Dissemination". Jones \& Asensio (2002) summarise an important literature on design for networked learning by interviewing some of the design practitioners themselves. The work by 
Reigeluth (1983) covers the field of Instructional Design (ID), which aims at improving the process of instruction or teaching and to prescribe 'effective' methods of instruction that would induce the desired changes in student knowledge and skills. Trehan and Reynolds (2002) emphasise the potential of collaborative assessment, especially on-line mechanisms, by examining its rationale from a critical perspective. Their on-line collaborative assessment involves learners having to assess their own and others' learning through negotiation of criteria and methods of assessment, whilst others argue (Reynolds \& Trehan, 2000) that it can also create anxiety, uncertainty and stress.

Hegarty, Phelan, and Kilbride (1998) provide a blueprint for building an interactive classroom for distance teaching and learning. They discuss the factors including teaching method, environmental factors, voice and video considerations that would affect remote learning and the effectiveness of available technologies such as video-conferencing discussion and audio-visual media. Crawford and Kevill (2000) introduce an on-line version of self-test and self-evaluation environment. It uses the Quiz Module of WEBCT, which employs an underlying item bank of over 700 questions. Kemm, Kavnoudia, Fritze, and Williams (2000) introduce a student-centred collaborative learning environment (CLE) as a replacement to formal lectures. Central to the environment is the facility for students to learn in small groups with the computer being an interactive medium to guide, prompt and assist the group or individuals learning. The tasks within the CLE session are designed to encourage peer learning and peer teaching. McMahon and Oliver (2000) present the case for consolidating a Bachelor of Communications program in which around 600 students will complete an introductory course in digital technologies in Edith Cowan University. They discuss the multiple levels of learning, critical design elements and strategies to support these needs towards different levels.

There is no doubt that IT has changed education fundamentally and the positive impacts of IT on education are overwhelming. IT has opened the door for many people to access knowledge and learning. IT provides facilities that individualize the education process, thereby accommodating student needs in terms of time, location, interests, propensities and learning styles. The engagement of IT with education has expanded educators' capabilities to improve educational standards and to deliver more qualified and effective education and educational systems and environment (Schacter, 1999). Large-scale, comprehensive and generalized studies, such as ACOT in last decade (NSBA, 2005; Schacter, 1999), have concluded that students in technology-rich environments have shown positive outcomes in achievement, learning interests and attitude. IT has seeded the building of such environments through computer-assisted instruction, integrated learning and simulation teaching systems, and collaborative network systems (Schacter, 1999). Further building blocks include the following:

1. Digital libraries, on-line books and course materials and on-line information browsing provide unlimited and unconstrained access to various educational resources.

2. Remote education systems, E-learning systems and virtual classrooms provide learning opportunities to students worldwide without space, time and location concerns.

3. Video conferencing, discussion over the Internet and voice over the Internet have saved time and, further, made learning more comprehensive and interesting.

4. Email and discussion boards provide facilities for effective communication and developing personal interests.

5. Auxiliary tools, such as Internet search engines and digital thesauruses provide such conveniences to students as the on-line quiz, electronic assignment submission and so on.

6. Special needs of particular students can also be addressed with suitably designed software systems. 
Educators have also benefited from this IT revolution in some of the following ways:

1. IT facilitates effective management of the education system. Student on-line enrolment, group email, and intranet make large education systems more manageable and productive.

2. IT allows teachers to spend less time on cumbersome paper work, to access comprehensive resources and to bridge effective collaboration between peers.

3. IT simulation software and video conferencing help educators create and deliver more interesting and effective course content.

4. IT allows effective interaction and communication between remote educators and students.

However, some of the drawbacks of IT to education include the following: E-learning alone can lead to reduced development of social and cultural communication skills and eliminate interaction required in the case of peer-to-peer learning. Further, the benefits of IT are restricted to those who have access to required technologies, thereby seeding a "digital divide" in education also. In addition, there are also concerns with regard to the reliability of the underlying technologies (ELearning guru, 2005; US Department of Education, 2005).

\section{Distributed Distance Learning}

There appear to be three types of distributed distance learning that allow instructors, students, and content to be located in different, non-centralized locations so that instruction and learning occurs independent of time and place. They are: the Virtual Learning Environment (VLE) (Dillenbourg, 2000), the Managed Learning Environment (MLE) (Joint Information Systems Committee [JISC], 2004) and the Virtual University (VU). Their Distributed Learning Models can be used in conjunction with traditional classroom-based courses, with traditional distance learning courses, or can be used to create wholly virtual classrooms. Note that, however, since educational resources are stored digitally rather than on bookshelves, library services need to be more closely integrated with the learning environment (Littlejohn, 2003).

The Virtual Learning Environment (VLE) (Dillenbourg, 2000) is a structure created on the Web, where all aspects of a traditional learning environment can be placed (also known as 'learning management system' (LMS)) along with the tools for their management and facilitation. It should also enable the provision and management of content and resources required in helping to make the activities successful towards learning and teaching as well as administrative functions from enrolment through to assessment results and careers advice.

The Managed Learning Environment (MLE) (JISC, 2004) includes the wider features of enrolment, course options management, student record and profile keeping. In addition, it caters for the wider management, interchange, publication of content and has features needed to allow learners to move or progress between courses and institutions.

The Virtual University (VU) (Connick, 1999) is an offshoot of a traditional institution offering a variety of programs and courses.

A number of VLES/LMSs are now available in the market including WebCT (http://www.webct.com/), Blackboard (http://www.blackboard.com), Colloquia (2004) (http://www.colloquia.net/), Co-Mentor (Catherine, 2004), Lotus LearningSpace (http://www.lotus.com/lotus/offering3.nsf/wdocs/learningspacehome) and COSE (2004) (http://www.cose.org/). Implemented and managed properly, distributed distance learning allows students to be more than just interactive, but also engages them in the learning process. Furthermore, the use of chat rooms and both synchronous and asynchronous moderated discussion groups means that students have the opportunity to learn from each other and discover knowledge and meaning among themselves (Fallows \& Bhanot, 2002). 
This paper deals with a Pedagogical Reference Oracle for Virtual IntegrateD E-ducation, called PROVIDE, which is aimed at providing an interactive educational environment over both in-situ and distance-based modalities of teaching. PROVIDE offers a seamless distributed environment for continuous interaction with both peers and instructors. PROVIDE also facilitates learning's "third dimension" in that learning in PROVIDE can be observed, monitored and enhanced on an on-going basis. The third dimension in learning relates to depth and perspective in learning, transforming ideas into action and ultimately extending individuals and the organisation into the commitment for continued learning during their on-going life time (see for example [http://www.tirian.com/3d/]). Teachers provide the third dimension in learning with their particular method of teaching, specialised oratory and/or stylised skills, observations and on-the-spot improvisations. In this paper, we allow technology to provide some aspects of these skills so that the $3^{\text {rd }}$ dimension in learning could be attempted. PROVIDE keeps a profile on the learning of an individual so that it can proactively manage the process and offer alternate courses of action where required. The PROVIDE framework includes tools and technologies for cooperation and collaboration. Furthermore, PROVIDE is also populated with a suite of testing and certification tools in order to provide individuals with a choice of learning procedures. In addition, PROVIDE's value-added services include offering organizations to have a certified means to meeting their on-going commitments to continuing education. We expect PROVIDE to be actively deployed and used in the near term (first 5 years) as a virtual learning environment, and we expect it to become a major source in education for "Digitally Empowered Learning".

According to the PROVIDE philosophy, learning occurs through four facets, namely, 1) through what is taught by a teacher, 2) through what is learnt by the students' own intellect, 3) through peer (interactive) learning and 4) through the process of hands-on experience. The underlying philosophy of PROVIDE has been considerably inspired by Barthruhari's (circa 400AD) monumental work on education, according to which, learning occurs through four facets: a fourth from a Guru or a teacher, a fourth from self-learning, a fourth from peer-learning and a fourth from experience (or case-based learning). More details on this philosophy are beyond the scope of this paper. In the past, the teacher directly interacted with the students through visual clues and aided their learning. Further, the place of learning provided sustained mechanisms, such as on-going assessment, which extends the students' thinking in order to augment their own intellect. Further, some places provided teaming processes to augment further learning through peer-to-peer learning. However, it has always been difficult to pass on the experiences through teaching alone. In this project, we attempt to enhance all four methods of learning and in addition, attempt to implement them through our E-education framework, PROVIDE.

In a typical electronic distance learning environment, it is not possible to monitor students' learning due to absence of visual clues; this is typically called the "third dimension" in learning and teaching (see for example http://www.tirian.com/3d/). Fortunately however, distance learning provides other clues, such as monitoring and observing the navigation profiles and the interaction profiles of students. Technologies such as electronic whiteboards and blackboards have been used to observe the behaviours. However, such technologies still are not capable of providing the third dimension in learning. We provide the use of information space (described below) as the new mechanism for achieving better annotations in learning and these issues include, but are not limited to, observability and monitoring ability.

We therefore believe that PROVIDE offers a distributed, yet integrated, virtual learning environment. In this paper, we describe some of the tools and technologies for PROVIDE that have already been developed and integrated, and in addition, we describe other tools currently under development. The rest of the paper is organized as follows: the following section covers various issues and techniques that underpin the system, and following that, system architectural issues are 
presented. There is then a comprehensive discussion of the issues arising out of our research work; and the conclusion summarises the paper and offers pointers for further R\&D work in this area.

\section{PROVIDE Issues and Tools}

The PROVIDE research has several dimensions, some of which have already been made concrete through a variety of earlier work done by both ourselves and other researchers. The following sections describe the methods and techniques that form the core of PROVIDE. The architectural aspects of PROVIDE are covered separately in section 3.

\section{Language Specification Issues}

The PROVIDE system incorporates our earlier work on architectural specifications, primarily achieved through CORBA IDL (Common Object-oriented Resource Broker Architecture Interface Definition Language) and CIDL (Component Interaction Definition Language). A suitable wrapper facility is also available so that existing services can be readily ported over the PROVIDE framework.

\section{System Analysis Issues}

Cooperation and collaboration tools, such as whiteboards, blackboards and groupware products are nominally available in many education-directed information systems. However, the need for co-ordination and the lack of bandwidth often are vital impediments to their usage. Such technologies need to marry appropriate compression technologies in order to be effective. A progressive compression scheme with a suitable quality of service metric enforced on it would be more than adequate. Furthermore, our system offers shared voice board (using voice-over IP technology) and, where bandwidth is available, a shared video board also. It has been empirically observed in industrial service support systems, that interactive voice technology offers a significant degree of customer satisfaction and it is expected that PROVIDE will also benefit in the same way.

The Virtual Learning Environment offers several facilities, including but not limited to the following:

- No need to "fix" the time for instruction delivery

- The need for physical commuting is replaced by High-tech telecommuting

- Learning material is presented through outsourced technical support, which is available 24 hours, 7 days a week over the whole year.

- Testing of the learned material is through an outsourced support.

- The entire learning and testing methodology is completely self-organized.

- Peer-interaction during learning is also completely self-organized.

- Learning is organized at student's own pace.

- The mobility of a student is not affected in any manner as the virtual environment can be "carried by the student".

- Intelligent instant messaging support provides peer-support environment also.

- On-line help in the form of admission support (e.g., pre-requisites), administration (e.g., due date, assignment information dissemination), virtual classroom support and virtual laboratory support with and without tutor support is also available. 
- Annotations and feedback are available through a number of mechanisms. For example, students can choose to let their learning sessions be observable and/or monitorable by experts from behind so that deficiencies in learning can be pinpointed. In addition, an expert can choose to point out certain good learning patterns, which can aid faster learning. Indeed it has been observed that learning patterns offer significant help in providing better learning and that "progression without intervention" can be better implemented. A suitable form of FAQ service which has a knowledge-based persistence (so that inter-session knowledge can be maintained in order to answer queries with context-in-sense) can improve the overall learning process significantly.

- Testability for learning and acquisition of knowledge can also be achieved. In addition, several certification methodologies, such as self-certification, mediated certification (where certification is done by a separate professional body) and professional enhancement programs (in the case of organizational learning) and their certification requirements are envisaged to be fully automated. The entire process is peer-review driven with periodic feedback available to the right people. The workflows between various services themselves are well-organized. The foundations to the PROVIDE environment are three latent services, which are: i) an Agentbased engine, which aids the composition of services and entities, ii) an inference generation and maintenance service and iii) a workflow management service.

\section{Application Issues}

The PROVIDE system can be applied and tailored to several learning environments from software engineering education to medical education through to arts and science education; but the system needs to be tailored for each application environment. Other application issues include: support for course materials, version controlling the materials, automatic update generation, etc. Some of these issues are complex and will not be addressed in this paper.

\section{Evaluation Issues}

Evaluation of PROVIDE will be done in several ways: technology evaluation will be achieved through the development of a capability technology demonstrator, which will be deployed over an actual classroom environment. The learning methodologies will be evaluated through a variety of feedback - both on-line and off-line - mechanisms. Several automated tools have already been identified for the management of feedback and annotations.

\section{System Architectural Issues and Its Information Space}

The PROVIDE Information Space is a dynamic distributed collaborative working environment, whose architecture, as shown in Figure 1, has a collection of peer-to-peer (P2P) services, Business-to-Business (B2B) services and Business-to-Customer (B2C) services, such as the following: Cooperation Service, Annotation Service, Expertise Service, Testing Service, Certification Service and Management Service. PROVIDE employs the Model Driven Architecture (MDA) (OMGa, 2004) philosophy of the Object Management Group (OMGb, 2004) and consequently it will be truly independent of considerations due to platforms, operating systems and underlying (computer) languages. Enterprise solutions such as DCOM and RMI will become operable under this CORBA environment. In the following sections, we present the details of these services and their operational capabilities. It is further noted that the architectural framework being adopted is itself an innovation as it brings out the entire system as a seamless integrated entity over a distributed environment to all types of users (viz., users/students, teachers, testers and experts). 


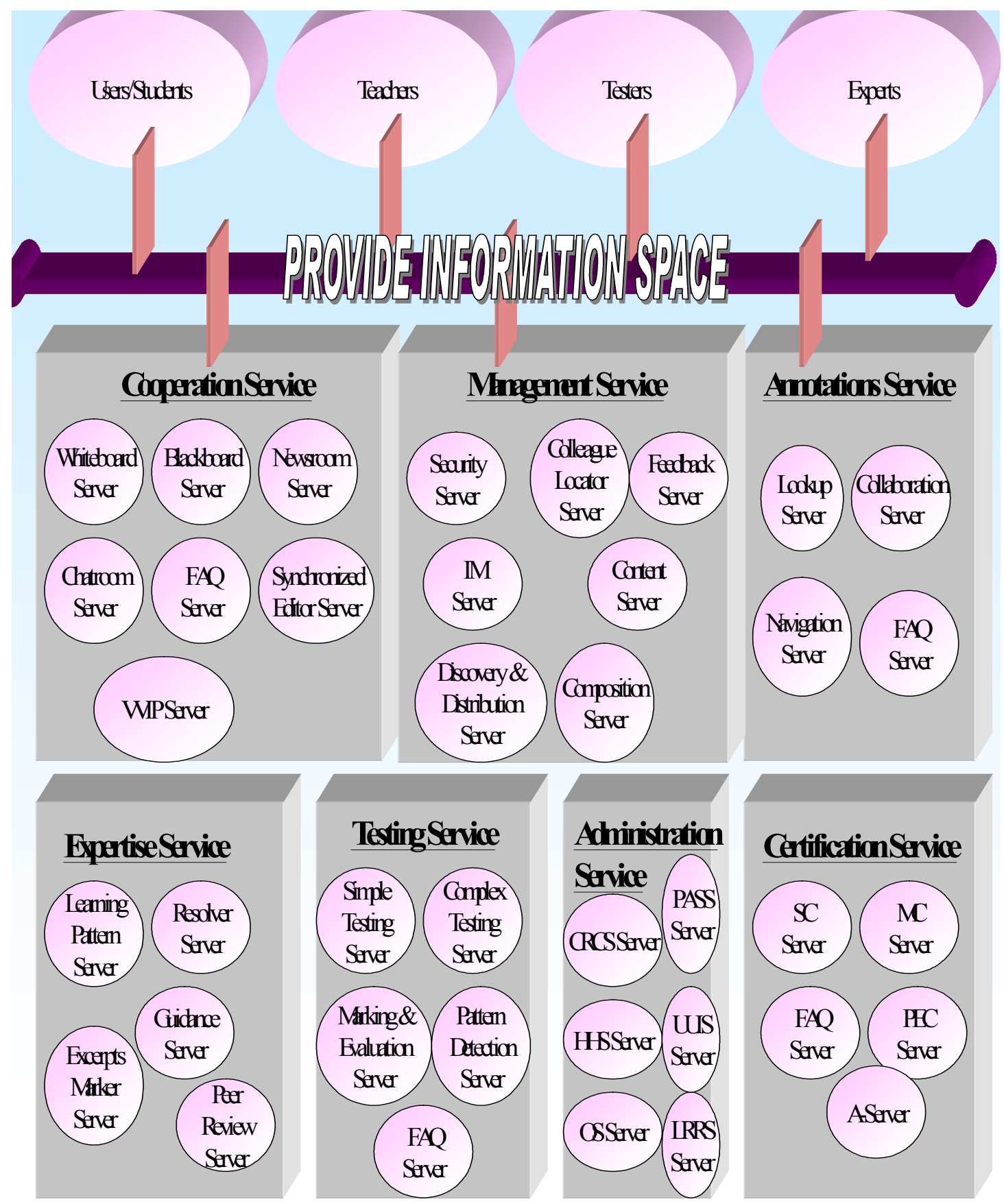

Figure 1: Architecture of the PROVIDE System

\section{Cooperation Service}

Most elements of the Cooperation Service have been developed or implemented by ourselves and other researchers, but further research is required to define and develop other services. It has seven sub-services, which include: a shared whiteboard, shared blackboard, newsroom, chat room FAQ server and a synchronized editor. Further to this, we provide a Voice \& Video over IP (VVIP) server, which provides a shared voice board, whereby one can conduct discussions using Voice over IP technology and deploy VXML and shared video board, which is similar to the shared voice board facility. 


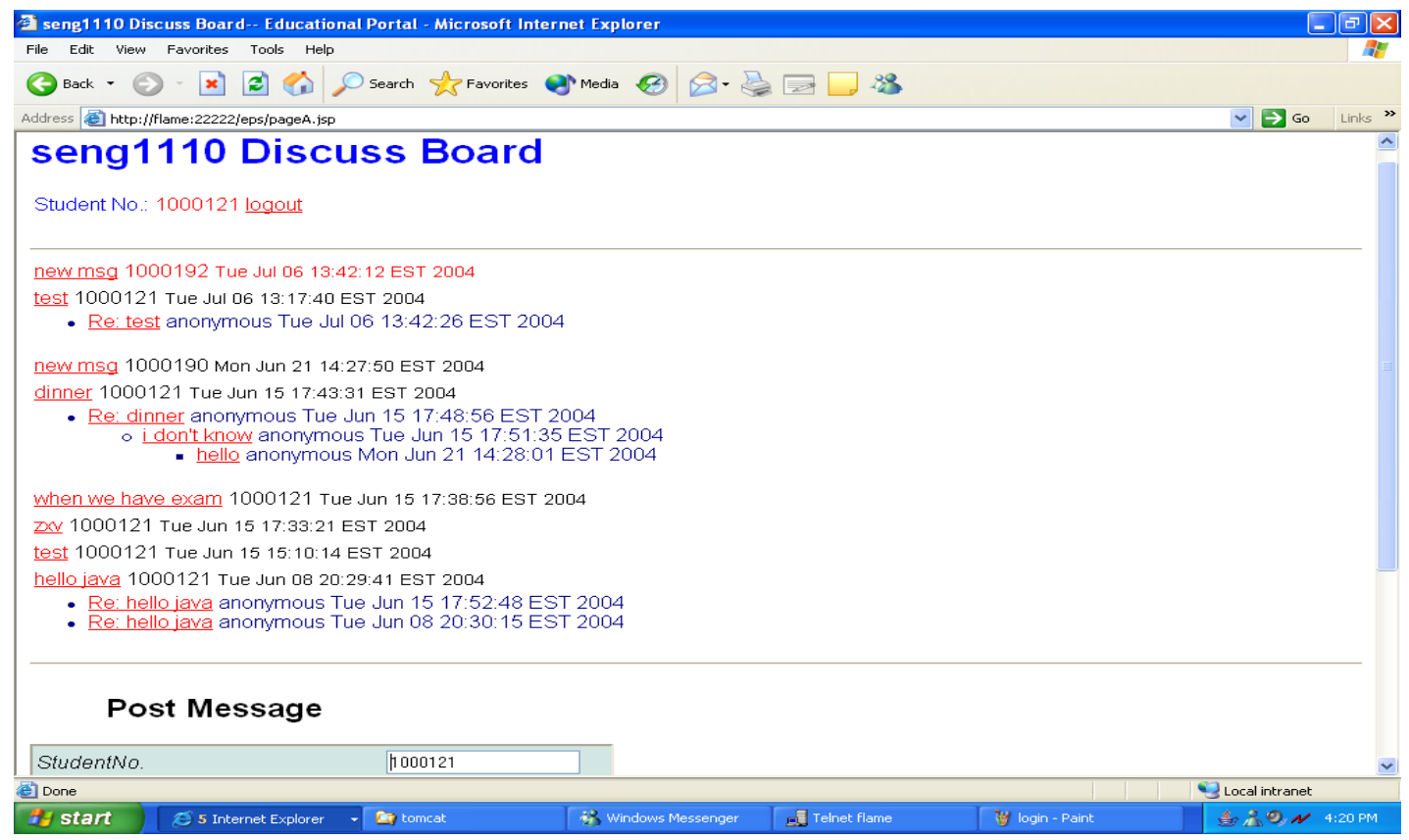

Figure 2: A Typical Main Board in PROVIDE

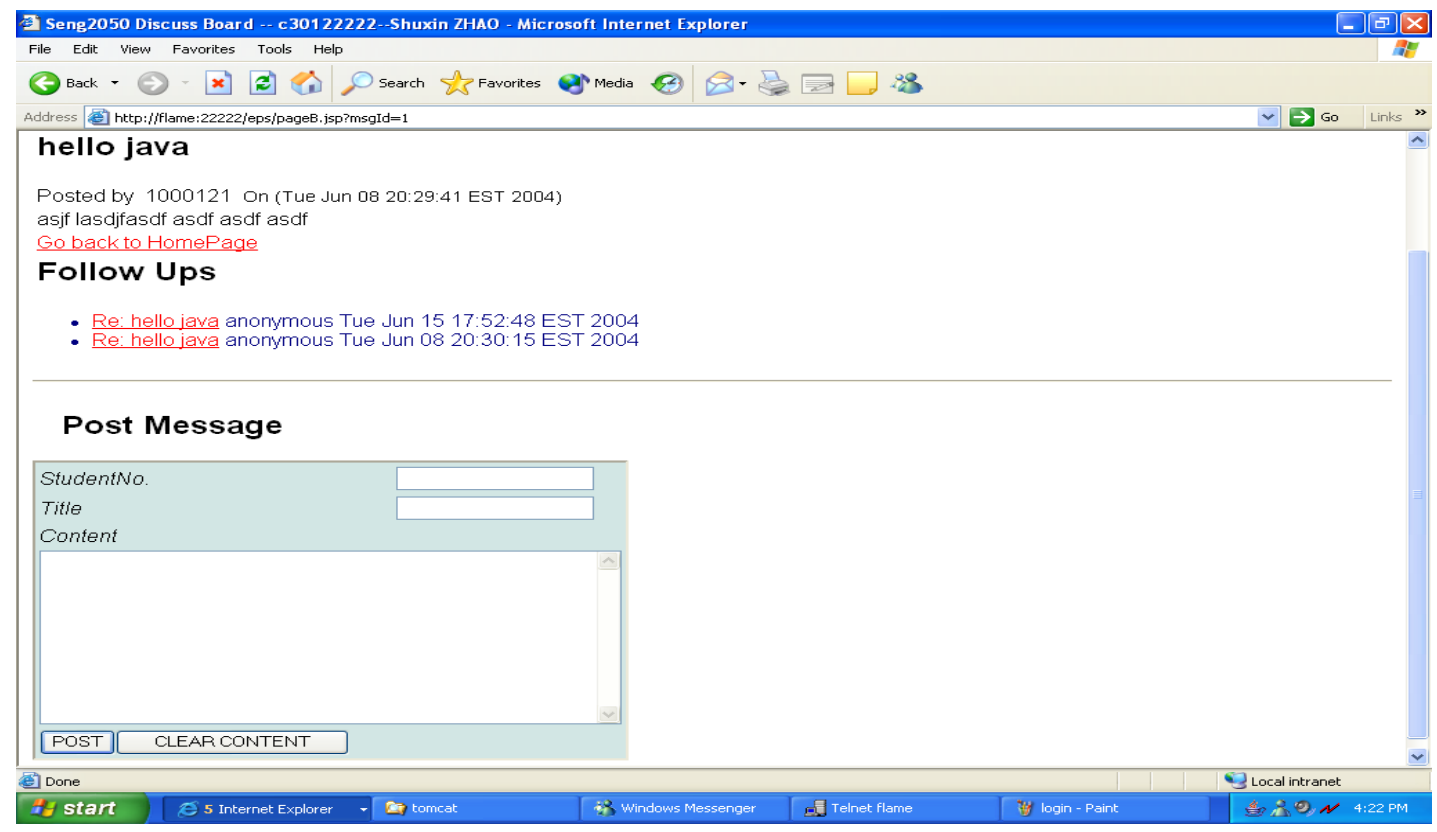

Figure 3: A Typical Message Content in PROVIDE

Figure 2 shows a sample user interface for the Discussion board (one for each subject), available within the Blackboard service. Figure 3 shows the view of the discussion message including contents and related messages. Users can reply to the message by using the "Post Message" function.

\section{Management Service}

The management service is the heart of the PROVIDE system, which offers a number of subservices that form the core architecture of PROVIDE. It has the following seven sub-services. 


\section{Information management server (IMS)}

The IMS provides facilities for information management that includes; XHTML, XML, VXML and VRML based mark-up of documents so that text, audio and video information can be managed properly. An agent-based architecture provides the means to handle issues towards conformance to IT standards, tagging, auto-summarization and information extraction. While some technologies are available to meet current expectations, they are neither robust not stable.

\section{Content server (CS)}

The aim of the Content Server is to detect, manage, organize and present content-related information. The discovery of content is achieved at run-time through various techniques such as shallow parsing, statistical based parsing and through pattern detection, which permit automatic extraction of content and topic. Such tools already exist both from other researchers (e.g., LSI from Tennessee University) and companies (Telcordia Technologies (2004) and n-Gram fromW3C (2004)) and through the authors' efforts in information extraction. Through this project we further intend to augment this capability through the deployment of agent-based technology.

\section{Discovery \& distribution server (DDS)}

The DDS server concerns the discovery and distribution of objects in the intergalactic information space. Such objects include shared whiteboards, blackboards, various tools and protocol resolvers (such as tools to convert XHTML to PDF for example). Analysis of performance (and of their penalties) is critical for the PROVIDE system, as the rate of learning is closely correlated to the system performance - an effective and efficient DDS server can help users learn more quickly.

\section{Composition server (COS)}

The Composition Server builds the system dynamically as per the user profile and dynamic requirements. Considerable research in distributed systems technology is required in terms of specifying components, characterizing their dynamic behaviours and managing their "fit-for-

composition" aspects. Specific issues addressed here include mechanisms for dynamic composition of courses and the development of purpose-built systems. Below we describe the former aspect in more depth. There are two roles available within the course composition service, namely, Student and Expert. The pseudo code for the composition service for the Student role is shown in Figure 4:
Load faculty
Load school according to faculty
Load subject according to school
Load course according to subject code
Load chapter according to course

\section{Add chapters to composition course}

Submit the composition course with chapters' details and student number

If the number of chapters $<10$

Display error message

Else

insert into tbltemp_c_course

Submit the composition course to expert 
Note that an expert will decide whether the composed course is suitable for the student or not.

\section{Note:}

1. tbltemp_c_course is a table to save the composed course details.

2. Note that the Student can choose chapters from different faculties.

If a superior level has been changed, the inferior levels have to be changed also. For example, items in School, Subject, Course and Chapter have to execute the related changes, if a Faculty item is changed.

\section{Figure 4: Pseudo Code for the Composition Service}

Figure 5 shows how to use the composition service for a Student role. In this case, the Student selects a chapter (e.g., chapter id 21 in Figure 5) as a chapter of his/her newly composed course.

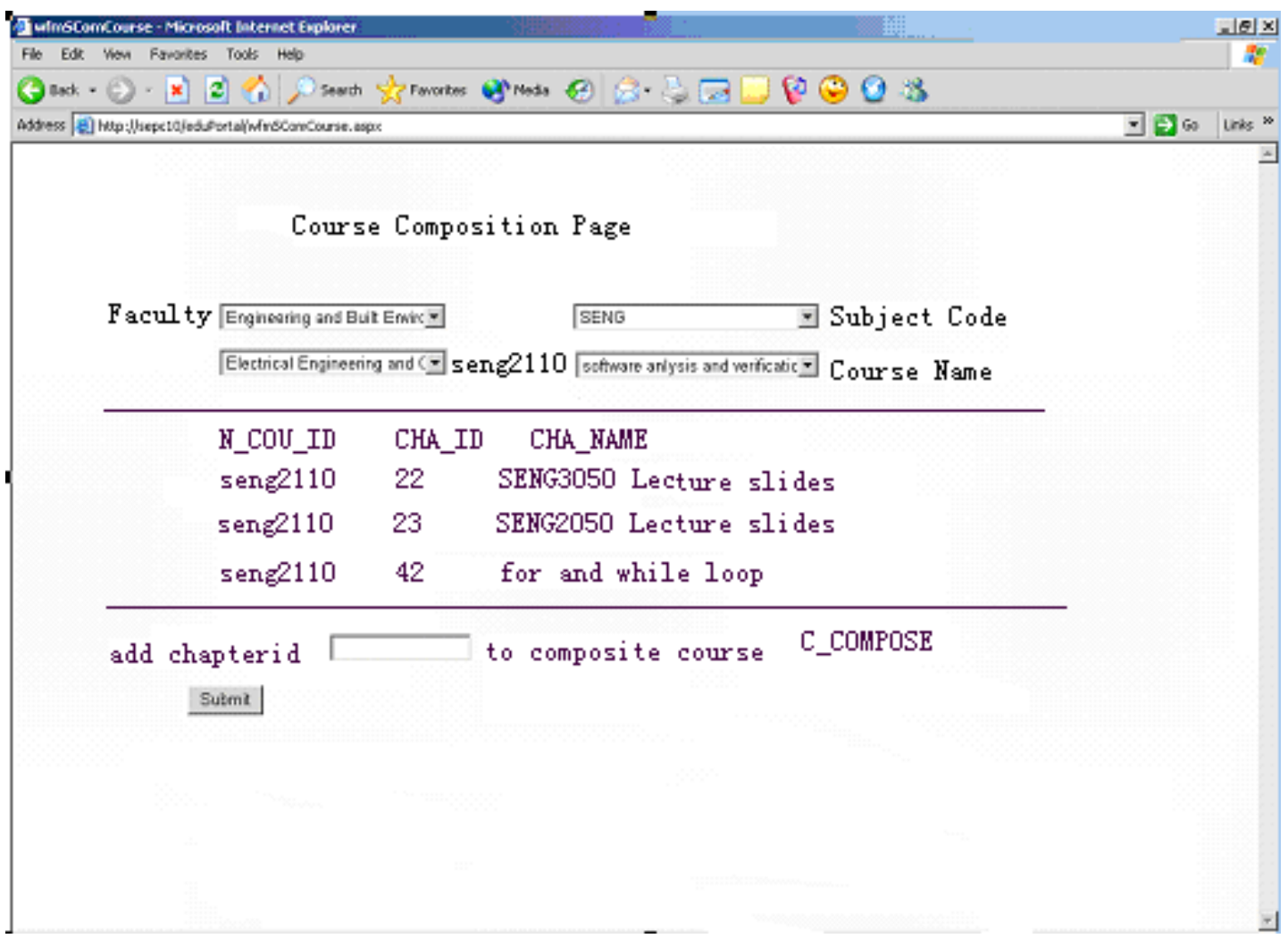

Figure 5: An Example of the Composition Service

\section{Colleague locator server (CLS)}

The colleague locator server is a pair of White page and Yellow page servers, which aid the location of subject modules, suitable teachers and testers. 


\section{Feedback server (FS)}

The FS offers facilities for managing feedback to various types of users of the service. This service is automatically included in certain cases of service offered and/or provided within the system.

\section{Security server (SS)}

The Security Server provides suitable security cover for the various types of services and their operations. This is based on Kerberos security protocol.

\section{Annotation Service}

The annotation service provides four sub-services, whose functions and descriptions are provided in the following paragraphs.

\section{Collaboration server (CIS)}

The Collaboration Server offers a proactive collaboration service judged after monitoring a student's learning behaviour. As a consequence, it is an optional service included upon request by a student. The collaboration can also be "on-the-fly" if and where required. Thus for example, if the collaboration server is included, dynamic query service is automatically invoked along with the expertise service (see below), so that appropriate type and nature of collaboration can be suggested to the user. Specifically, if a student is learning, say programming in Java Swing Layout Manager, then appropriate sections of the manual and codes will be prompted to the student, if and when required or requested.

\section{Lookup server (LS)}

The Lookup Server is a pair of White Page and Yellow Page servers, which aid the location of a suitable annotation tools and protocols for various types of users. For example, a student user could use this server to locate a suitable visual debugger that works under a particular system (operating system version, language version and configuration).

\section{Navigation server (NS)}

The navigation marker server provides auto-navigation and user-tailored and/or expert guided navigation facilities for learning a particular topic or organizing a program of study.

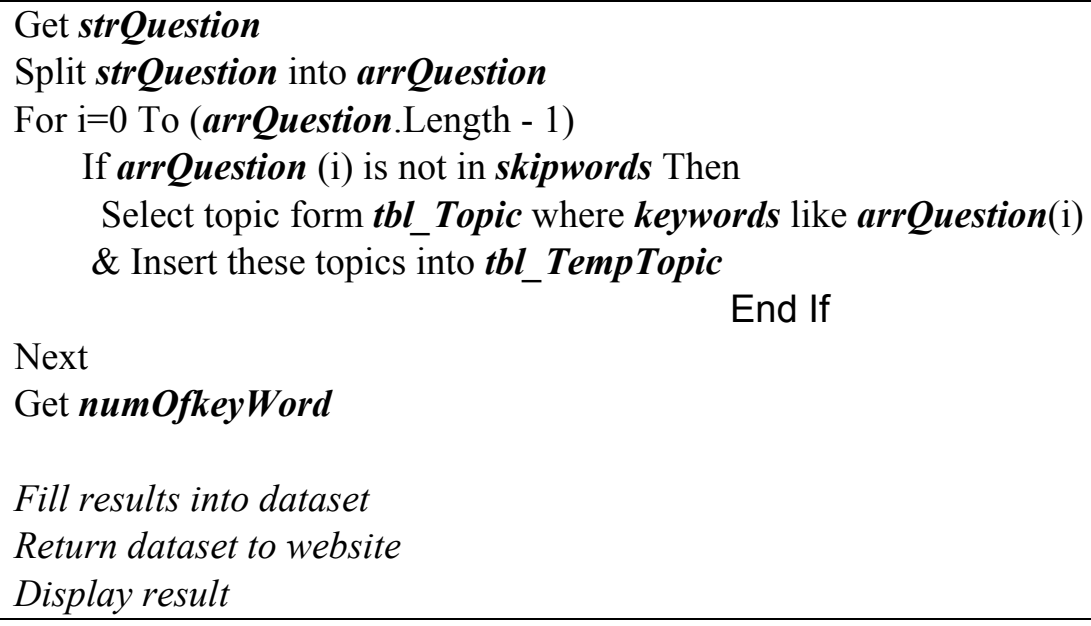




\author{
Drop tbl_TempTopic \\ If result is null \\ Insert strQuestion into $t b l \_N A \_Q u e s t i o n$ \\ End If
}

Notes:

StrQuestion is question sentence input from user.

ArrQuestion is an array to save the formatted question.

tbl_Topic is table in server. Its columns are top_id, content, description, keywords.

tbl_TempTopic is a temporary table for storing the temporaty keyword matching result.

numOfkeyWord is the number of question's keywords.

NumOfID is the number of a top_id in tbl_TempTopic.

Skipwords is an array that stores the words set that should be ignored in during searching. Its elements like \{"and", "are", "for", "how", "in", "is", "it", "of", "on", "or", "the", "to", "what", "where"\}

"arrQuestion (i) is not in skipwords": use binary search here

tbl_NA_Question is a table in server to save the questions without answer temporarily.

\title{
Figure 6: Pseudo Code for the FAQ Server
}

\section{FAQ server}

This server offers both simple and persistent FAQ on the various annotations made on the learning and the learned parts. Note that whilst a simple FAQ may be relatively simple to design, the design of a persistent FAQ server demands innovative marriage between suitable AI and knowledge representation technologies. The pseudo code for the FAQ service is shown in Figure 6.

Figure 7 shows the use of the FAQ service, whereby users enter their questions - for example "What is Java?" and select the question type (normal question or related to course content). The service searches the underlying database and displays the matching answers.

\section{Expertise Service}

The expertise service offers five sub-services, whose descriptions are given below.

\section{Resolver server (RS)}

The resolver service is called in when there is a (perceived) mismatch in the advice given by one of the annotations service. This is an advanced service, which has not been implemented.

\section{Learning pattern server (LPS)}

The learning pattern server provides patterned learning over a particular topic or environment as a guide to the user. This is an advanced service, which has not been implemented.

\section{Guidance server (GS)}

The guidance server simply offers guidance over a series of topics or courses so that a particular program of activity can be taken up by a student. 


\section{FAQ Service}

My Question is:

What is Java

Fromtext book

Find Answer

\begin{tabular}{|c|c|}
\hline Description & Content \\
\hline Java Bean knowledge & http://www.cs.newcastle.edu.au/ seng2050/lectures/lect04.pdf \\
\hline Java Servlet knowledge & http://www.cs.newcastle.edu.au/ seng2050/lectures/lect03.pdf \\
\hline how to use GUI in java & http://www.cs.newcastle.edu.au/ seng1110/slides/L04b2.pdf \\
\hline how to use if command in java & http://www.cs.newcastle.edu.au/ seng1110/slides/L03a2.pdf \\
\hline how to use testing in java & http://www.cs.newcastle.edu.au/ seng1110/slides/L03c2.pdf \\
\hline how to use while command in java & http://www.cs.newcastle.edu.au/ seng1110/slides/L03b2.pdf \\
\hline java basic knowledge & http://www.cs.newcastle.edu.au/ seng1110/slides/L02b2.pdf \\
\hline java basic knowledge & http://www.cs.newcastle.edu.au/ seng1110/slides/L02c2.pdf \\
\hline java introduction & http://www.cs.newcastle.edu.au/ seng1110/slides/L01b2.pdf \\
\hline more class descriptions in java & http://www.cs.newcastle.edu.au/ seng1110/slides/L06a2.pdf \\
\hline more class descriptions in java & http://www.cs.newcastle.edu.au/ seng1110/slides/L06b2.pdf \\
\hline more methods in java & http://www.cs.newcastle.edu.au/ seng1110/slides/L04c2.pdf \\
\hline more methods in java & http://www.cs.newcastle.edu.au/ seng1110/slides/L05a2.pdf \\
\hline
\end{tabular}

Figure 7: An Example of the FAQ Service

\section{Peer review server (PRS)}

PRS provides peer review service on a particular problem, subject area or a program. The peer review is a user-pay service.

\section{Excerpts marker server (EMS)}

EMS oversees the production and marking of excerpts over a "learned material" (typically an answer sheet) or a questionnaire sheet.

\section{Testing Service}

The testing service has five sub-services, whose functions and descriptions are listed below:

\section{Simple testing server (STS)}

The STS server is involved in the looking up of a suitable MES service so that testing can be accomplished (say over a topic or a subject).

\section{Complex testing server (CTS)}

The CST server is involved in the looking up of a suitable MES service so that testing can be accomplished (say over an entire program or courses).

\section{Pattern detection server (PDS)}

The PDS server detects patterns in learning, plagiarism and the like. This is an advanced service, which has not been implemented. 


\section{Marking \& evaluation server (MES)}

The MES server identifies accredited markers/evaluators for a subject, program and/or their certification by an approved body.

\section{FAQ server}

The FAQ server offers FAQ on the various operations of the certification service. As noted before, this FAQ server also offers persistence services using AI and knowledge management services.

\section{Certification Service}

Certification service is essential for providing certification to both individuals and organizations. It has five sub-services, whose functions are listed as below.

\section{Self-Certification server (SCS)}

The SCS provides the mechanics of self-certification over a particular subject or course.

\section{Mediated certification server (MCS)}

The MCS provides the mechanics of mediated certification over a particular subject or course. The MES service has to be used in conjunction with this service.

\section{Peer evaluated certification server (PECS)}

The PECS provides the mechanics of peer certification (i.e., someone or some Peer-Evaluation Body other than the instructor) over a particular subject or course. Obviously, a MES service has to be employed to accomplish this service to completion.

\section{Accreditation service (AS)}

The AS provides accreditation to courses, test procedures, tests and markers/evaluators.

\section{FAQ server}

The FAQ service provides clarifications on the various operations of the certification service.

\section{Administration Service}

The administrative service caters for the day-to-day administration requirements of the users of PROVIDE. It has six sub-services, whose functions are described as below:

\section{Pre-requisite advisor server (PAS)}

The PAS is a fully automated service which advises prospective students of a particular course or a particular program and their pre-requisites

\section{Hand holder server (HHS)}

The HHS is meant for novice users of all types so that they can easily navigate through the various system functions. This is a highly interactive service, which can handle natural language-like queries. 


\section{Class room support server (CRSS)}

The class room support server manages the list of virtual classrooms available to all types of users so that a proper alignment with various programs can be made.

\section{Listener, recorder \& reminder server (LRRS)}

The LRRS is responsible for maintaining a listener and/or a recorder for each virtual classroom session. It also provides an additional reminder service to all types of users.

\section{Outsourced services (OS)}

The outsourcing service is meant for outsourcing the delivery of a particular course or a program. All policies and procedures related to this are managed through this service.

\section{Uniform user interface service (UUIS)}

Uniform interface is critically important for all types of users under all conditions of use. A browser-based environment is provided to every user, which can be reconfigured to create the look-and-feel of a student's preferred learning environment.

\section{Discussion}

The PROVIDE environment offers a comprehensive list of services. Further, the use of mainstream distributed technologies like Java RMI, CORBA, DCOM and CBSE (Component Based Software Engineering) provides graduate students with a large variety of opportunities to work on research theses, projects and venture undertakings, depending on their interests and backgrounds. The continuation of industrial partnerships related to PROVIDE allows undergraduate students to obtain quick training in high demand domains related to networking, service provision, interoperability and Java/C++ technologies.

PROVIDE has the following significance to the educational research:

- Since PROVIDE emphasises more student-teacher participation, fundamental issues in training and on-going advice, including evolutionary and incremental guidance can be better achieved.

- Our belief in peer learning and "progression without intervention" can be tested and proven.

- PROVIDE is a distance-learning tool, which offers the "third dimension" in learning.

- The system can be easily tailored to various types of users - from novice student type to experts who are new to the system.

- Since the process of accreditation is uniform across PROVIDE, quality and assurance procedures can be developed to the highest degree of conformance.

- Certificate programs, higher degree programs and professional enhancement programs can now be readily offered over the PROVIDE environment, which will hopefully reduce the turn-around time for learning. Thus development and deployment of knowledge workforce is likely to be hastened considerably.

PROVIDE has the following significance to information engineering research:

- The PROVIDE system imparts practical education and training in recent technical areas such as software engineering, distributed object computing and agent technology. 
- Since the system is component-based and agent-oriented, interoperability can be readily achieved. Indeed, we believe PROVIDE itself will become a test-bed for successful operation for interoperability over a distributed virtual environment.

- We anticipate the development of technology demonstrators, prototypes and other facilities over PROVIDE. An "immersion facility" (with the use of VRML), which allows multiple users to "experience" the same experience that a single user gets, is envisaged in the future.

- Value-added assistance to portal development and suitable IT franchising is very possible.

We also expect the core research tools and technologies (particularly on software engineering and underlying distributed tools and systems management) to be taken up by large application developers in a variety of areas, such as medical informatics, simulation and war gaming, defence and government communities. Since the core technologies are common to most application domains, we anticipate the technology transfer and knowledge transfer times to be low.

Presently a High Performance Java and CORBA based PROVIDE implementation is available offering a limited number of services. We are currently in the process of specifying a comprehensive Agent Programming Library containing implementations of key Mobile Agent based Design Patterns. Further a secure network layer, code compression, advanced adaptive compiler with mobile code specific optimizations and multiple transport layers for multicast sockets, and several foundation services required for PROVIDE are also being investigated. A controlled Natural Language Processor and Speech I/O module, Multi-User Shared Virtual Agent based environment design and development are also taking place in parallel through various Honours and Graduate student programs. Application for real life testing and evaluation of our tools, complete test set, system documentation and advancement report generation are areas, where development work has not yet started. However, basic services of PROVIDE are already operational and can be accessed from www.newcastle.edu.au/ narasimhan/PROVIDE.

\section{Conclusions}

In this paper we have presented a seamless distributed interactive educational environment for both teaching and learning. We have discussed auxiliary technologies and tools as well as related design issues. We have described the PROVIDE framework architecture, which contains a collection of peer-to-peer (P2P) services. PROVIDE permits learning to occur through four facets, namely, 1) through formal teaching over distance learning, 2) through self-learning, 3) through peer (interactive) learning and 4) through the process of hands-on experience. We provide an open software system to students so that students can select what they want to learn from different courses and, further, compose those segments in order to form a new course. PROVIDE encourages students to study actively following their particular interests and needs. The system also provides peer-to-peer learning through blackboard and whiteboard facilities. Several forms of FAQ services are provided to the user. Each FAQ service has two parts: normal and academic so that users can get the right answer quickly. Since the system is component-based, it permits code and component re-use. Further intelligent agent technology is used to bind the system components, which further aid system evolution. We also expect the further research to be taken up by large application developers in a variety of areas, such as providing voice and video boards over high speed networks.

In this paper, we have also provided a comprehensive discussion on the opportunities arising from the research. Related research work on this area done by other researchers has also been discussed. Several milestones for the proposed system have been met to date, while others are being attended to. Future R\&D work of this project includes the complete realization of the proposed framework in a progressive manner. 


\section{Acknowledgements}

We thank the four referees and Editor Mike Hart, for their extensive comments, which improved the quality of the paper considerably.

\section{References}

Barthruhari. (Circa 400 CE). Subhashitham: A treaty on education and learning in Sanskrit.

Carr, S. (2000). As distance learning comes of age, the challenge is keeping the students. Retrieved from Chronicle of Higher Education, February 11, 2000. Retrieved from http://www.chronicle.com/free/v46/i23/23a00101.htm

Catherine, S. (2004). CoMentor. Retrieved August 12, 2004, from http://www.socresonline.org.uk/2/3/comentor.html

Colloquia. (2004). The Innovative Learning Management and Groupware System. Retrieved August 12, 2004, from http://www.colloquia.net/

Connick, G. (1999). The distance learner's guide. Upper Saddle River, NJ: Prentice-Hall.

COSE. (2004). The small business division of the greater Cleveland partnership. Retrieved 12 August, 2004, from http://www.cose.org/

Crawford, P. \& Kevill, R. (2000). Computer assisted learning: A formative approach. In Apple Computer Australia, Apple University Consortium Academic and Developer's Conference 2000: New millennium, new technology, new world of learning. Wollongong, N.S.W.: Apple Computer Australia.

Dillenbourg, P. (2000). Virtual learning environments. In EUN conference 2000: Learning in the new millennium: Building new education strategies for schools. Retrieved August 12, 2004, from http://tecfa.unige.ch/tecfa/publicat/dil-papers-2/Dil.7.5.18.pdf

E-Learningguru. (2005). Retrieved March 20, 2005, from http://www.elearningguru.com/articles/art1_3.htm

Fallows, S., \& Bhanot, R. (2002). Educational development through information and communications technology. St Ives plc: Clays Ltd.

Fritze, P., Welch, S. R., \& Ji, G. (2000). Foundations of a component framework for rich on-line learning activities. In Apple Computer Australia, Apple University Consortium Academic and Developer's Conference 2000: New millennium, new technology, new world of learning. Wollongong, N.S.W.: Apple Computer Australia.

Ganesan, R., Edmonds, G. S., \& Spector, J. M. (2002). The changing nature of instructional design for networked learning. In C. Steeples, \& C. Jones (Eds.), Networked learning: Perspectives and issues. London,UK: Springer-Verlag.

Gilbert, S.D. (2001). How to be a successful on-line student. New York: McGraw-Hill.

Harasim, L.M. (1998). The Internet and intranets for education and training: A framework for action. In C. De Moura Castro (Ed.), Education in the information age. New York: Inter-American Development Bank.

Harasim, L., Hiltz, S.R., Teles, L., \& Turoff, M. (1995). Learning networks: A field guide to teaching and learning on-line. Cambridge, MA: The MIT Press.

Hegarty, M., Phelan, A. \& Kilbride, L. (Eds.) (1998). Classrooms for distance teaching \& learning: A blueprint. Leuven, Belgium: Leuven University Press.

Joint Information Systems Committee [JISC]. (2004). Managed Learning Environment (MLE). Retrieved August 12, 2004, from The Joint Information Systems Committee Web site:

http://www.jisc.ac.uk/index.cfm?name=mle home 
Jones, C. \& Asensio, M. (2002). Designs for networked learning in higher education: A phenomenographic investigation of practitioners' accounts of design. In C. Steeples, \& C. Jones (Eds.), Networked learning: Perspectives and issues. London, UK: Springer-Verlag.

Kemm, R. E., Kavnoudia, H., Fritze, P., \& Williams, N.T. (2000). A computer-facilitated collaborative learning environment for tertiary students. In Apple Computer Australia, Apple University Consortium Academic and Developer's Conference 2000: New millennium, new technology, new world of learning. Wollongong, N.S.W.: Apple Computer Australia.

Kouki, R., \& Wright, D. (1999). Telelearning via the Internet. Hershey, PA: Idea Group.

Ling, P., Arger, G., Samllwood, H., Toomey, R., Kirkpatrick, D, \& Barnard, I. (2001). The effectiveness of models of flexible provision of higher education: Evaluations and investigations program. Australia: Department of Education, Training and Youth Affairs.

Littlejohn, A. (2003). Reusing on-line resources: A sustainable approach to E-learning. Sterling, VA: Kogan Page Limited.

Maehl, W.H. (2000). Lifelong learning at its best. San Francisco: Jossey-Bass.

Mayes, T., Dineen, F., Mckendree, J., \& Lee, J. (2002). Learning from watching others learn. In C. Steeples, $\&$ C. Jones (Eds.), Networked learning: Perspectives and issues. London, UK: Springer-Verlag.

McMahon, M., \& Oliver, R. (2000). Building self-supporting websites to accommodate large numbers of students. In Apple Computer Australia, Apple University Consortium Academic and Developer's Conference 2000: New millennium, new technology, new world of learning. Wollongong, N.S.W.: Apple Computer Australia.

NSBA. (2005). Retrieved March 20, 2005, from http://www.nsba.org/sbot/toolkit/whytech.html

OMGa. (2004). The Architecture of choice for a changing world. Retrieved August 12, 2004, from Object Management Group Web site: http://www.omg.org/mda/

OMGb. (2004). Retrieved August 12, 2004, from http://www.omg.org/

Palloff, R.M., \& Pratt, K. (2001). Lessons from the cyberspace classroom: The realities of on-line teaching. San Francisco: Jossey-Bass.

Peterson, P.W. (2001). The debate about on-line learning: Key issues for writing teachers. Computers and Composition, 18(4), 57-70.

Reigeluth, M. C. (1983). Instructional-design theories and models: An overview of their current status $\left(2^{\text {nd }}\right.$ Ed.). New Jersey: Lawrence Erlbaum Associates.

Reynolds, M. \& Trehan, K. (2000). Assessment: A critical perspective. Studies in Higher Education. Retrieved August 30, 2004, from http://0proquest.umi.com.newcutter.newcastle.edu.au/pqdweb?RQT=318\&pmid=34505.

Rowan, L., Barllell, L. \& Evans, T. (eds.) (1998). Shifting borders: Globalisation, localisation and open and distance education. Geelong, Victoria, Australia: Deakin University Press.

Schacter, J. (1999). The impact of education technology on student's achievement. Retrieved March 20, 2005, from http://www.milkenexchange.org

Telcordia Technologies. (2004). Telcordia Latent Semantic Indexing (LSI). Retrieved August 12, 2004, from http://lsi.research.telcordia.com

Trehan, K. \& Reynolds, M. (2002). On-line collaborative assessment: Power relations and 'Critical Learning '. In C. Steeples, \& C. Jones (Eds.), Networked learning: Perspectives and issues. London, UK: Springer-Verlag.

US Congress. (2004). Retrieved August 1, 2004, from Office of Technology Assessment Web site. http://www.ota.nap.edu/index.htm

US Department of Education. (2005). Retrieved March 20, 2005, from http://www.ed.gov 
Narasimhan, Zhao, Liang, \& Zhang

W3C. (2004). Stochastic Language Models (N-Gram) Specification. Retrieved August 12, 2004, from http://www.w3.org/TR/ngram-spec

\section{Biographies}

Prof. Lakshmi Narasimhan obtained his Bachelor's degrees in Physics and Electronics Engineering from the University of Madras and Indian Institute of Science respectively. He also obtained his Master's and Phd degrees respectively from the Madras Institute of Technology and University of Queensland, Australia. He worked at his alma mater in Australia as a lecturer and senior lecturer and was also the Director of the PA3SE (Parallel Algorithms, Architectures And Software Engineering) Research Laboratory. In 1995 he moved to the Australian Defence and Science and Technology Organisation (DSTO) as a Principal Research Scientist and was leading the program on Information Management and Information Fusion. He has been instrumental in initiating few key computer information systems projects with strategic clients within the Australian Defense Force, which have since led to the deployment of several mission critical systems at various customer sites. Later he moved to the USA, where worked as a full professor at the Computer Science Department, University of North Texas at Denton. Currently he is the Professor and Chair in Software Engineering at the University of Newcastle, Australia.

Prof. Narasimhan has published over 120 papers in the areas of Software Engineering and Information Engineering. In particular, his research interests are in computer architecture, parallel and distributed computing, software testing, text $\&$ audio processing, E-Commerce, Software process, and information management $\&$ fusion. His papers have appeared in such archival journals as the various IEEE Transactions and IEE Proceedings. Prof. Narasimhan was the founding chair of the IEEE Computer Society, Queensland Chapter and initiated the International Conference series ICA3PP (IEEE International Conference on Algorithms And Architectures) and acted as its Inaugurating Chair. He has also been the technical chair of two other conferences and has been on the technical panel of over 30 leading International Conferences. Currently his research interests are the areas of large-scale system engineering, testing \& visualization, Agent technology for Decision Support System design and distributed object computing. He has consulted to a number of industries and educational institutions on various IT and Software Engineering projects. Presently he is also associated with two Co-Operative Research Centres (CRC on Construction Innovation and CRC on Integrated Engineering Asset Management). He is also the Director of the MESTEC Research Centre at the University of Newcastle, which specialises in the applications of mobile technology to medical information management and patient care. Prof. Narasimhan is a Senior Member of the IEEE, ACM, Fellow of ACS and IEAust. He is an (technical) Expert Panel Member of ISO (International Standards Organisation) and MIMOSA (Machinery Information Management Open Standards Organisation, USA).

Shuxin Zhao has a master's degree in information technology with a major in software engineering, and a diploma in enterprise management. She has been working at the University of Newcastle as a research assistant since July 2004. Her research interests are focused on system integration, with emphasis on schema matching, and ontology based knowledge modeling. She has previously worked as system developer and designer in an IT company in Beijing.

Liang Hailong graduated from Mathematics School of Peking University of China in 2000 with a major in Computing Mathmatics \& Softerware. In 2002, Liang Hailong completed a master's degree in information technology at the Newcastle University. He also completed a MEM (Master of Engineering Management) degree in the Newcastle Graduate school of Business of Newcastle University in 2004.

Shuangyi Zhang completed a master's degree in information technology at the Newcastle University. Currently he is working for an IT company in China. 